Cochrane Database of Systematic Reviews

\title{
Rituximab for treating inhibitors in people with inherited severe hemophilia (Review)
}

Jiang L, Liu Y, Zhang L, Santoro C, Rodriguez A

Jiang L, Liu Y, Zhang L, Santoro C, Rodriguez A.

Rituximab for treating inhibitors in people with inherited severe hemophilia.

Cochrane Database of Systematic Reviews 2017, Issue 7. Art. No.: CD010810.

DOI: 10.1002/14651858.CD010810.pub3.

www.cochranelibrary.com 
HEADER 1

ABSTRACT

PLAIN LANGUAGE SUMMARY

BACKGROUND

OBJECTIVES

METHODS

RESULTS

Figure 1.

DISCUSSION

AUTHORS' CONCLUSIONS

ACKNOWLEDGEMENTS

REFERENCES

APPENDICES

WHAT'S NEW

CONTRIBUTIONS OF AUTHORS

DECLARATIONS OF INTEREST

SOURCES OF SUPPORT

DIFFERENCES BETWEEN PROTOCOL AND REVIEW

INDEX TERMS

\section{TABLE OF CONTENTS}


[Intervention Review]

\section{Rituximab for treating inhibitors in people with inherited severe hemophilia}

Lucan Jiang1,2,3,4, Yi Liu1,2,3,4, Lingli Zhang1,2,3, Cristina Santoro5, Armando Rodriguez 6

1Department of Pharmacy, West China Second University Hospital, Sichuan University, Chengdu, China. 2Key Laboratory of Birth Defects and Related Diseases of Women and Children, Sichuan University, Ministry of Education, Chengdu, China. ${ }^{3}$ Evidence-Based Pharmacy Center, West China Second University Hospital, Sichuan University, Chengdu, China. ${ }^{4}$ West China School of Pharmacy, Sichuan University, Chengdu, China. ${ }^{5}$ Department of Cellular Biotechnology and Hematology, Sapienza University of Rome, Rome, Italy. 6 Association for the Promotion of Multimedia Education, Zagreb, Croatia

Contact address: Lingli Zhang, Department of Pharmacy, West China Second University Hospital, Sichuan University, No. 17, Section Three, Ren Min Nan Lu AvenueRoad, Chengdu, Sichuan, 610041, China. zhlingli@sina.com.

Editorial group: Cochrane Cystic Fibrosis and Genetic Disorders Group.

Publication status and date: New search for studies and content updated (no change to conclusions), published in Issue 7, 2017.

Citation: Jiang L, Liu Y, Zhang L, Santoro C, Rodriguez A. Rituximab for treating inhibitors in people with inherited severe hemophilia. Cochrane Database of Systematic Reviews 2017, Issue 7. Art. No.: CD010810. DOI: 10.1002/14651858.CD010810.pub3.

Copyright $(2017$ The Cochrane Collaboration. Published by John Wiley \& Sons, Ltd.

\section{A B S T R A C T}

\section{Background}

Hemophilia A and B are inherited coagulation disorders characterized by a reduced or absent level of factor VIII or factor IX respectively. The severe form is characterized by a factor level less than 0.01 international units (IU) per milliliter. The development of inhibitors in hemophilia is the main complication of treatment, because the presence of these antibodies, reduces or even nullifies the efficacy of replacement therapy, making it very difficult to control the bleeding. People with inhibitors continue to have significantly higher risks of morbidity and mortality, with considerable treatment costs. Given the wide 'off-label' use of rituximab for treating people with hemophilia and inhibitors, its efficacy and safety need to be evaluated. This is an update of a previously published Cochrane Review.

\section{Objectives}

To assess the efficacy and safety of rituximab for treating inhibitors in people with inherited severe hemophilia A or B.

\section{Search methods}

We searched the Cochrane Cystic Fibrosis and Genetic Disorders Group's Coagulopathies Trials Register, complied from electronic database searches and handsearching of journals and conference abstract books. We searched the reference lists of relevant articles and reviews and also searched for ongoing or unpublished studies. We also undertook further searches of other bibliographic databases and trial registries.

Date of last search of the Cochrane Cystic Fibrosis and Genetic Disorders Group's Coagulopathies Trials Register: 16 February 2017.

\section{Selection criteria}

Randomized controlled trials and controlled clinical trials investigating the efficacy and safety of rituximab for treating inhibitors in people with hemophilia.

\section{Data collection and analysis}

No randomized controlled trials matching the selection criteria were eligible for inclusion.

\section{Main results}

No randomized controlled trials on rituximab for treating inhibitors in people with hemophilia were identified. 


\section{Authors' conclusions}

We were unable to identify any relevant trials on the efficacy and safety of rituximab for treating inhibitors in people with hemophilia. The research evidence available is from case reports and case series. Randomized controlled trials are needed to evaluate the efficacy and safety of rituximab for this condition. However, prior to the publication of any possible future randomized controlled trials, meta-analysis of case reports and case series may provide some evidence.

\section{PLAIN LANGUAGE SUMMARY}

\section{Rituximab for treating inhibitors in people with inherited severe hemophilia}

\section{Review question}

We reviewed the evidence available to see if rituximab is effective and safe when treating clotting factor inhibitors in people with severe hemophilia. This is an update of a previously published Cochrane Review.

\section{Background}

Hemophilia A and B are inherited conditions in which there is either reduced levels (or none at all) of factor VIII (hemophilia A) or factor IX (hemophilia B) in the blood. In severe forms there are undetectable levels of these factors (less than 0.01 international units (IU) per milliliter). People with hemophilia are at risk of bleeding events which can occur spontaneously or after trauma or invasive medical procedures. Therefore, they need to be treated with factor concentrates, either in reaction to these events or preventatively. Unfortunately, about $30 \%$ of people with severe hemophilia A and $1 \%$ to $6 \%$ of people with severe hemophilia B can develop antibodies (inhibitors) against factor VIII or factor IX, because the factors are not recognized by the immune system. The development of inhibitors is the main complication of hemophilia treatment, because their presence reduces or cancels out the beneficial effects of replacement therapy, making it very difficult to control bleeding. Moreover, when inhibitors are present, it is impossible to start preventative treatment with factor VIII or factor IX concentrates. Therefore, it is important to eliminate the inhibitors and allow treatment to proceed successfully. The 'off-label' use (currently unapproved for treating people with hemophilia) of rituximab, has shown in some studies an effect on eliminating inhibitors in people with hemophilia. Therefore, we wanted to see whether using rituximab was better than the standard treatment or other therapies without rituximab, and whether it is safe, and could save these people from life-threatening hemorrhage and huge financial expense.

\section{Search date}

The evidence is current to: 16 February 2017.

\section{Key results}

We did not find any randomized controlled trials assessing rituximab in people with severe hemophilia. Well-designed controlled trials are needed to assess the benefits and risks of using rituximab in people with hemophilia. Until controlled trials are published, only limited and low-level evidence, based on individual cases, can guide physicians in making clinical decisions. 


\section{B A C K G R O U N D}

For a glossary of terms used in this review please refer to the appendices (Appendix 1).

\section{Description of the condition}

Hemophilia is a rare, inherited, X-linked, recessive disorder in which the blood does not clot normally (NHLBI 2011). The severe form is characterized by a factor level less than 0.01 international units (IU) per milliliter ( $\mathrm{mL}$ ). Treatment consists of administering factor VIII (FVIII) concentrate (for hemophilia A) or factor IX (FIX) concentrate (for hemophilia B) on demand when bleeding occurs, or prophylactically to prevent bleeding (Coppola 2012; Iorio 2011). Inhibitors, neutralizing antibodies toward FVIII or FIX, can occur when the body's immune system does not recognize clotting factor concentrates as self protein (WFH 2013). These inhibitors reduce or even nullify the efficacy of factor concentrates.There are several known risk factors for the occurrence of inhibitors; either genetic risk factors (nature of gene defect, ethnicity); or nongenetic risk factors (intensive factor exposure at the time of surgery, and prophylactic or on-demand treatment regimens) (Iorio 2010a). The source of FVIII used for replacement therapy may also have an effect on inhibitor development. Studies have shown that for previously untreated patients (PUPs) with severe hemophilia A, high-dose intensive FVIII treatment increases the risk for inhibitor development, but low-dose prophylactic treatment decreases it, especially in those with low-inhibitor-risk FVIII genotype mutations (Gouw 2007a; Gouw 2013a). Although much debated, recent studies have suggested no significant difference in the risk of inhibitor development in PUPs between recombinant and plasma-derived FVIII concentrate therapy (Gouw 2007b; Gouw 2013b). A clinical trial randomizing PUPs to either plasma-derived or recombinant FVIII concentrates is ongoing (SIPPET trial) and is expected to provide further high-quality evidence to clarify the issue (NCT01064284).

Blood screening can show the presence of a bleeding disorder. The activated partial thromboplastin time (APTT) assay often suggests the presence of inhibitors, when it is not corrected (either at all or partially) by mixing with normal plasma. The Nijmegen assay is performed to confirm diagnosis, which can determine the titer of inhibitors (Verbruggen 1995). The amount of inhibitors in the blood is measured in Bethesda Units (BU), where a level of more than five $\mathrm{BU}$ is referred to as 'high titer' and less than five $\mathrm{BU}$ as 'low titer' (WFH 2012a). Inhibitors usually occur between the first 10 to 20 exposure days and therefore most often develop in childhood. Approximately $30 \%$ of children with hemophilia A (Gouw 2013b), and 1\% to $6 \%$ of individuals with hemophilia B (WFH 2012b), develop inhibitors. In people with hemophilia, sometimes the bleeding is spontaneous; surgical operations and strenuous exercise can also be precipitating factors for acute bleeding.

People with hemophilia and inhibitors commonly receive bypassing agents to treat acute bleeding episodes and immune tolerance induction (ITI) to eradicate the inhibitors. Bypassing agents, such as recombinant-activated FVII concentrate (rFVIIa) or activated prothrombin complex concentrate (aPCC), are insensitive to inhibitors (Iorio 2010b). As an alternative, and where resources are not a limitation, bypassing agents can be used prophylactically (Leissinger 2011). In hemophilia A, the standard treatment, ITI, consists of the regular infusion of FVIII concentrate in an attempt to achieve immunologic tolerance. Success is no different between using a high- or low-dose ITI regimen, although a high-dose regimen may achieve success more rapidly (Hay 2012). People with hemophilia B and high-titer FIX inhibitors may also be treated with ITI, although this approach is less frequently successful than for people with hemophilia A (DiMichele 2007). However, ITI is expensive and not always effective for everyone; it requires specialized medical expertise over a long period of time.

People with inhibitors continue to have significantly high risk for morbidity and mortality, with considerable treatment costs. The ultimate eradication of inhibitors remains the most challenging treatment issue in people with severe hemophilia.

\section{Description of the intervention}

Many immunomodulatory approaches have been studied in the search for more effective techniques to eradicate clotting factor inhibitors. The chimeric monoclonal antibody, rituximab, seems to be a particularly promising agent. In 1997, the USA's Food and Drug Administration (FDA) approved rituximab, also known as MabThera ${ }^{\circledR}$ (F. Hoffmann-La Roche Ltd., Pharmaceuticals Division, Basel, Switzerland) and Rituxan ${ }^{\circledR}$ (IDEC Pharmaceuticals, San Diego, CA, and Genentech, Inc, San Francisco, CA), for use in adult $\mathrm{CD} 20^{+}$B-cell lymphomas (Kavcic 2013). To date, this treatment is licensed for the following indications in adults: non-Hodgkin's lymphoma; chronic lymphocytic leukemia; rheumatoid arthritis; granulomatosis with polyangiitis (Wegener's granulomatosis); and microscopic polyangiitis (FDA 2013). In pediatric hematologyoncology departments, rituximab is widely used 'off-label' (Yadav 2012) to treat such diseases as chronic immune thrombocytopenia (Grace 2012), systemic lupus erythematosus (Nwobi 2008) and autoimmune hemolytic anemia (Kuzmanovic 2012). Given its 'offlabel' use, studies in the hemophilia population are limited. The standard single dose of rituximab for treating inhibitors is 375 $\mathrm{mg} / \mathrm{m}^{2}$, administered intravenously on a weekly schedule for four weeks. Rituximab is currently available in a $10 \mathrm{mg} / \mathrm{mL}$ concentrate of either $10 \mathrm{~mL}$ (100 mg) or $50 \mathrm{~mL}$ (500 mg) (Pescovitz 2006). The price in Italy is currently the equivalent of USD $575(100 \mathrm{mg})$ and USD 1445 (500 mg), while in the USA it is USD $568(100 \mathrm{mg})$ and USD 2840 (500 mg). It is an expensive drug and not covered by many insurance plans or by government funding.

\section{How the intervention might work}

Rituximab is a chimeric mouse-human monoclonal immunoglobulin $\mathrm{G} 1$ antibody against the CD20 antigen on the surface of B lymphocytes (Borker 2011). The binding of rituximab to $\mathrm{CD} 20$, which is a B-cell differentiation maker, may cause B-cell death in three ways, including complement-dependent cytotoxicity, stimulation of apoptosis, or antibody-dependent cell-mediated cytotoxicity (Selewski 2010). Rituximab targets the $\mathrm{CD} 2 \mathrm{O}^{+} \mathrm{B}$-cells, with a rapid and sustained elimination. Generally, rituximab is used as second-line treatment for inhibitors, in those resistant to standard ITI. It is hypothesized that rituximab, eliminating $B$ cells which produce inhibitors, can reduce the titer facilitating ITI in resistant cases. A national cohort in the UK has shown the efficacy of this treatment (Collins 2009). Rituximab has been used for treating people with hemophilia and inhibitors with a response rate up to 63\% (Borker 2011).

\section{Why it is important to do this review}

Two non-Cochrane systematic reviews have examined the literature on rituximab for treating children with hemophilia who express clotting factor inhibitors. One review, published in 2008, 
was based on studies including only people with congenital hemophilia (Franchini 2008). Another review, published in 2007, included eight children with hemophilia (Giulino 2007). These two reviews included only case reports and case series involving a relatively small number of participants, making the reviews potentially biased and imprecise. The two reviews were unable to draw definitive conclusions or make recommendations about using rituximab to manage hemophilia in people with inhibitors.

Although rituximab has become widely available as a therapy option, its high price and the lack of definitive evidence about its efficacy and safety remain barriers to its acceptance by patients and physicians. In an attempt to guide both groups as they decide on the most appropriate hemophilia treatment, we undertook a Cochrane systematic review to evaluate the efficacy and safety of rituximab to eradicate inhibitors complicating congenital hemophilia treatment. This is an update of a previously published Cochrane Review (Liu 2015).

\section{O B JE C T IVES}

To assess the efficacy and safety of rituximab in the treatment of inhibitors in people with severe hemophilia A or B.

\section{METHODS}

\section{Criteria for considering studies for this review}

\section{Types of studies}

Randomized and quasi-randomized controlled trials (RCTs; quasiRCTs). Controlled clinical trials would be considered if no RCTs or quasi-RCTs were found.

\section{Types of participants}

People of any age with confirmed congenital hemophilia A or B and inhibitors.

A positive inhibitor result is any result above the cut-off, measured by an assay that can quantify the level of the inhibitor (e.g. Nijmegen or Bethesda assay).

\section{Types of interventions}

Intervention group: intravenous rituximab, irrespective of dose or duration and interval of administration.

Control group: placebo, no treatment, intervention not involving rituximab or a different dose of intravenous rituximab.

Any adjunct therapy, if recommended or prescribed, should be given to both groups.

\section{Types of outcome measures}

\section{Primary outcomes}

1. Remission or no response (Hay 2012)

a. complete remission: negative inhibitor titer, FVIII recovery over $66 \%$ of expected, and FVIII recovery lasting longer than six hours

b. partial remission: negative inhibitor titer, but persistently abnormal recovery or half-life; responding clinically to FVIII replacement without an anamnestic increase in inhibitor titer

c. failure: failure of the inhibitor to decline by $20 \%$ over any six-month period; or failure to achieve tolerance or partial response; or withdrawal from the trial for any reason before tolerance was achieved

d. relapse: inhibitor recurrence during the 12-month followup period on prophylaxis after tolerance was achieved, as evidenced by recurrent positive Bethesda titer or a decline in FVIII recovery or half-life below trial limits

\section{Secondary outcomes}

1. Months to complete remission (time-to-event data)

2. Duration of remission (months)

3. Relapse rate following remission

4. Cost of care

5. Quality of life (e.g. as reported within trials or specifically using validated questionnaires)

6. All-cause mortality

7. Adverse drug reactions

\section{Search methods for identification of studies}

There were no restrictions regarding language or publication status.

\section{Electronic searches}

We searched relevant studies from the Cystic Fibrosis and Genetic Disorders Group's Coagulopathies Trials Register using the terms: haemophilia* AND rituximab.

The Coagulopathies Trials Register is compiled from electronic searches of the Cochrane Central Register of Controlled Trials (CENTRAL) (updated each new issue of the Cochrane Library) and weekly searches of MEDLINE and the prospective handsearching of one journal - Haemophilia. Unpublished work is identified by searching the abstract books of major conferences: the European Haematology Association conference; the American Society of Hematology conference; the British Society for Haematology Annual Scientific Meeting; the Congress of the World Federation of Hemophilia; the European Association for Haemophilia and Allied Disorders, the American Society of Gene and Cell Therapy and the International Society on Thrombosis and Haemostasis. For full details of all searching activities for the register, please see the relevant section of the Cochrane Cystic Fibrosis and Genetic Disorders Group's website.

Date of the most recent search of the Cystic Fibrosis and Genetic Disorders Group's Coagulopathies Trials Regsiter: 16 February 2017.

1. Bibliographic databases: we retrieved articles from the following databases: PubMed; Embase; the Chinese National 
Knowledge Infrastructure (CNKI) database; the Chinese Biomedical Literature Database (CBM); VIP; WANFANG; and LILACS. We searched all databases from their earliest records to 15 May 2017. Detailed search strategies are given in the appendices (Appendix 2; Appendix 3).

2. Trials registries: we searched OpenGrey (www.greynet.org/), Clinicaltrials.gov (https://clinicaltrials.gov/), and the WHO International Clinical Trials Registry Platform (ICTRP) (www.who.int/ictrp/en/) (searched using the terms: 'hemophilia' and 'rituximab')

3. We analyzed the websites of the following organizations to identify grey literature: the Canadian Hemophilia Society; the National Hemophilia Foundation; the National Heart, Lung and Blood Institute (USA); the Hemophilia Alliance.

\section{Searching other resources}

1. Researchers: we contacted the major researchers in this field to gather information on unpublished or ongoing trials.

2. Pharmaceutical companies: we contacted the pharmaceutical companies: F. Hoffmann-La Roche Inc.; IDEC Pharmaceuticals; and Genentech, Inc. for information on unpublished or ongoing trials.

3. Reference lists: we manually searched the reference lists of relevant reviews, systematic reviews and original research articles.

\section{Data collection and analysis}

Given that we did not identify any eligible trials, we did not apply the process below; however, if we include any trials in a future update, the following methods will be applied.

\section{Selection of studies}

Two authors will independently scan the titles and abstracts of all reports identified from the literature searches. The complete articles will be obtained if we need more information beyond what is in the title and abstract. Two authors will independently apply the inclusion criteria to identified articles in order to determine whether we should include these in the review or not. We will resolve disagreements by discussion among co-authors and, when necessary, with the Cochrane Cystic Fibrosis and Genetic Disorders Group. We will use reference management software to merge search results and remove duplicate records. We will also scrutinize each trial to ensure that no trial is reported in multiple publications. We will document reasons for excluding trials.

\section{Data extraction and management}

Two authors will independently extract data using pre-designed forms. These data will include characteristics of the trial design, participants, interventions and outcomes. The authors will test and optimize the data extraction form before extraction after a preliminary test. If data for a trial are incomplete, the review authors will contact the primary trial author for further information and clarification. The authors aim to detect and resolve any discrepancies by discussion and cross-checking.

If any included trials involve children and adults we will attempt to extract data separately for children. If any trials examine hemophilia A or B with inhibitors in addition to other hematological diseases, we will include these and attempt to extract the relevant data.

\section{Assessment of risk of bias in included studies}

Two authors will independently assess the risk of bias of included trials using a standardized assessment form. The authors will assess bias in RCTs across the following six domains according to the domain-based evaluation recommended in the Cochrane Handbook for Systematic reviews of Interventions (Higgins 2011a): sequence generation; allocation concealment; blinding of participants and personnel; blinding to outcome assessment; incomplete outcome data; and selective outcome reporting. If we are unable to obtain important information from the published trials, we will contact the primary author of the relevant trial. We will aim to resolve any disagreements by discussion.

\section{Measures of treatment effect}

To measure treatment effects, we will use the rate ratio (RR) for dichotomous data; we will also use the hazard ratios (HR) to measure time-to event data. We will use the mean difference (MD) for measuring continuous data. If trials report the same outcome on different scales which cannot be converted to the same unit, we will use the standardized mean difference (SMD). We will report all of these measurements with their corresponding 95\% confidence intervals $(\mathrm{Cl})$.

\section{Unit of analysis issues}

We will include cluster-randomized trials and cross-over trials along with individual-randomized trials. In this systematic review, we will treat each group or cluster in cluster-randomized trials as the unit of analysis; we will use the intracluster correlation coefficient (ICC) to estimate the relative variability within and between clusters, according to the relevant section of the Cochrane Handbook of Systematic Reviews of Interventions (Higgins 2011b). For cross-over trials with binary outcomes, we will adopt the Becker-Balagtas approach to combine cross-over trials with parallel trials for metaanalysis (Stedman 2011). For cross-over trials with continuous outcomes, each individual will act as the unit of analysis and we will conduct approximate paired analyses (Higgins 2011b).

\section{Dealing with missing data}

If data on individuals are missing, such as when randomized participants are excluded from the analysis, we will conduct intention-to-treat analyses. We will follow the principal options and adopt four general recommendations for dealing with missing data, as described in the Cochrane Handbook for Systematic Reviews of Interventions (Higgins 2011b). These are:

1. whenever possible, we will contact the original investigators to request missing data;

2. we will make explicit the assumptions of any methods used to cope with missing data: for example, that the data are assumed missing at random, or that missing values were assumed to have a particular value such as a poor outcome;

3. we will perform sensitivity analyses to assess how sensitive results are to reasonable changes in the assumptions that are made;

4. we will address the potential impact of missing data on the findings of the review in the discussion section.

If necessary, and possible, the authors plan to impute any missing standard deviations (SDs), following advice from chapter 16 of the 
Cochrane Handbook for Systematic Reviews of Interventions (Higgins 2011b).

\section{Assessment of heterogeneity}

The authors will identify any statistical heterogeneity among the included studies based on the $\mathrm{Chi}^{2}$ test $\left(\mathrm{X}^{2}\right.$ or $\left.\mathrm{Chi}^{2}\right)$ included in the forest plots. A P value of less than or equal to 0.1 will be taken as evidence of heterogeneity in treatment effects, and the $\mathrm{I}^{2}$ statistic will be used to quantify the heterogeneity. We will interpret the level of heterogeneity according to the Cochrane Handbook for Systematic reviews of Interventions (Higgins 2011a):

- $0 \%$ to $40 \%$, may not be important;

- $30 \%$ to $60 \%$, may represent moderate heterogeneity;

- $50 \%$ to $90 \%$, may represent substantial heterogeneity;

- $75 \%$ to $100 \%$, represents considerable heterogeneity.

The authors will also refer to the forest plots to see if the Cls overlap in order to further identify any possible heterogeneity.

\section{Assessment of reporting biases}

If we include 10 or more trials, the authors will use a funnel plot to detect small-study effects, including publication bias. We will use a linear regression approach proposed by Egger to test for funnel plot asymmetry (Egger 1997).

\section{Data synthesis}

The authors will use Review Manager software to analyze data (RevMan 2014). If the trials show homogeneity, we will carry out a meta-analysis of pooled research outcomes using a fixed-effects model. If the trials show substantial heterogeneity, we will use a random-effects model or describe the results narratively. If we are unable to undertake any meta-analyses, we will summarize the trial results in tables. We will describe the time to response and response duration with medians, minimum and maximum values. If we are able to include sufficient data, we will group outcome data for analysis at six months, one year and annually thereafter. However, if outcome data were recorded at other time periods, then we will consider examining these as well.

If rituximab is given as an adjunct therapy to ITI, these trials will be analysed separately from those in which rituximab is given alone.

\section{Subgroup analysis and investigation of heterogeneity}

If 10 or more trials are included, and if we identify heterogeneity $\left(I^{2}\right.$ equals more than $50 \%$ ), we plan to investigate this by performing the following subgroup analyses:

1. hemophilia groups: hemophilia A; hemophilia B;

2. treatment groups: rituximab alone; rituximab plus other treatment.

3. participants: PUPs; previously treated patients.

\section{Sensitivity analysis}

If the authors are able to include at least 10 trials in the review, we will perform a sensitivity analysis to determine whether the conclusions are robust to decisions made during the review process. We therefore plan to perform sensitivity analyses by reanalyzing the data statistically, such as using a fixed-effects model first and then a random-effects model, and vice versa.

\section{RE S U L T S}

\section{Description of studies}

No trials were found which were eligible for inclusion in the review.

\section{Results of the search}

No trials were found which were eligible for inclusion in the review (Figure 1). 
Figure 1. Study flow diagram.

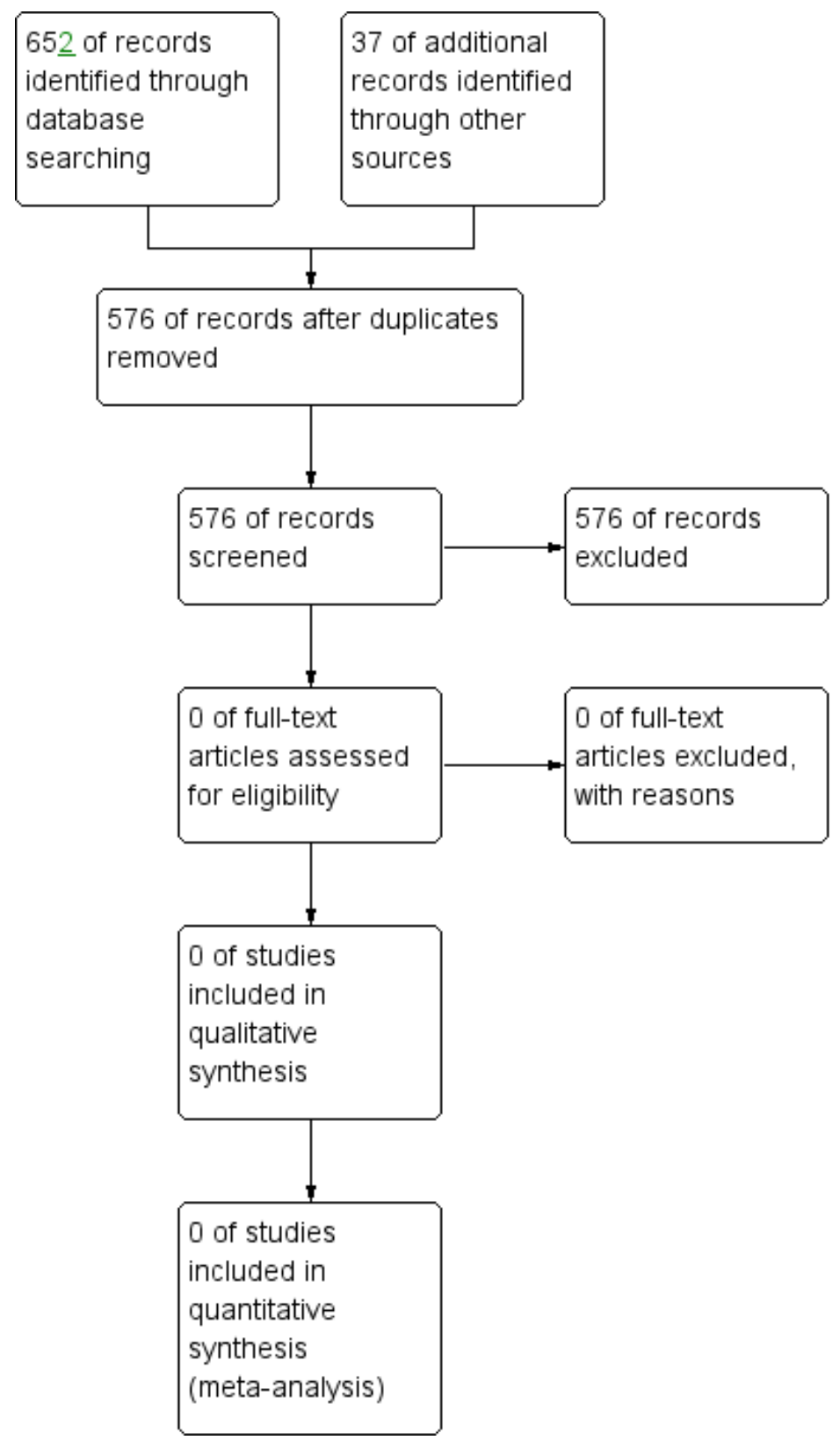

\section{Included studies}

No trials were found which were eligible for inclusion in the review.

\section{Excluded studies}

No trials were found which were eligible for inclusion in the review.

\section{Risk of bias in included studies}

No trials were found which were eligible for inclusion in the review.

\section{Effects of interventions}

No trials were found which were eligible for inclusion in the review.

\section{DISCUSSION}

\section{Summary of main results}

No controlled trials were identified which were eligible for inclusion in this review.

\section{Agreements and disagreements with other studies or reviews}

As described in the Background section, we are aware of two systematic review about rituximab for treatment of people with hemophilia and inhibitors (Franchini 2008; Giulino 2007). However, neither of them included any controlled trials. A total of 29 studies, with information on 49 cases were included in the Franchini review (Franchini 2008). The individuals included had congenital 
hemophilia A and B with inhibitors, were resistant to previous immune tolerance induction (ITI) regimens and were treated with rituximab (Franchini 2008). The dose of rituximab was $375 \mathrm{mg} / \mathrm{m}^{2}$ per week, with the total number of doses varying from 4 to 11 according to the individuals condition (Franchini 2008), although the four-dose schedule was the most common one (Collins 2009). Treatment with rituximab provided a durable remission in 26 out of 49 cases (53.1\%). However, the follow-up (three to 34 months) was not long enough and there is potential to overestimate the efficacy, as individuals who relapsed would be missed. The degree of disease severity was shown to be the primary influencing factor for the effect of rituximab, with those with mild and moderate disease showing a higher rate of response than those with severe hemophilia. In the Giulino review, eight children with congenital hemophilia were treated with rituximab for inhibitors. Five of these children (63\%) had an initial response, but two of them relapsed at 11 and eight months, respectively; only one of them responded to a second course of rituximab (Giulino 2007). For this update, we identified a new case report which reported on a successful treatment of an individual with hemophilia B with inhibitors using ITI with rituximab, who reported that the CD20positive lymphocyte count was a useful marker to guide ITI therapy (Kobayashi 2015).

Regarding safety issues, rituximab-related adverse reactions have been reported to include the following: sinusitis (Carcao 2006); nausea (Collins 2009; Fox 2006); dyspnea (Mateo 2006; Moschovi 2006); hypotension (Mateo 2006); urinary infection (Fox 2006); fever (Moschovi 2006); abdominal pain (Cooper 2006); and headache (Collins 2009). However, no severe adverse reactions have been reported for this disease (Collins 2009; Franchini 2008). First infusion-related side effects were common and mild (Franchini 2008; Giulino 2007).

In the absence of evidence from randomized controlled trials (or controlled trials), clinicians are only able to use information from observational studies of lower quality taking into account the limitations of doing so.

\section{AUTHORS' CONCLUSIONS}

\section{Implications for practice}

No randomized controlled trials (or controlled trials) on rituximab for treating inhibitors in people with hemophilia were found for inclusion in this review. Therefore, the research evidence in this area is based on case reports or case series, with the existing systematic reviews based on observational studies only.

\section{Implications for research}

This systematic review has identified the need for well-designed, adequately-powered randomized controlled trials to assess the benefits and risks of the use of rituximab for treating inhibitors in people with hemophilia, as a means of rescuing these people from life-threatening hemorrhage and huge financial expense.

The following questions should be addressed in any future RCTs.

1. What is the clinical effectiveness of rituximab for treating inhibitors in people with hemophilia?

2. Which dose and course is the most effective and safe?

3. What time is the best to administer rituximab?

4. How much will it cost until complete remission (if it can be achieved)?

5. The trials should consider the following clinical outcomes: time to complete remission; duration of remission; relapse rate; cost of care; and quality of life.

The limited number of potential participants and ethical considerations may be barriers for any future randomized controlled trials. Before the publication of these results, metaanalysis of case reports and case series may provide higher quality evidence than single case reports.

\section{ACKNOWLEDGEMENTS}

Many thanks to all authors' affiliated institutions and organizations, and thank the Co-ordinating Editor, referees and Editors of the Cochrane Cystic Fibrosis and Genetic Disorders Group for their comments and encouragement.

This project was supported by the National Institute for Health Research, via Cochrane Infrastructure funding to the Cochrane Cystic Fibrosis and Genetic Disorders Group. The views and opinions expressed therein are those of the authors and do not necessarily reflect those of the Systematic Reviews Programme, NIHR, NHS or the Department of Health. 


\section{R E F E R N CE S}

\section{Additional references}

\section{Borker 2011}

Borker A, Choudhary N. Rituximab. Indian Pediatrics 2011;48(8):627-32.

\section{Carcao 2006}

Carcao M, St Louis J, Poon MC, Grunebaum E, Lacroix S, Stain AM, et al. on behalf of the Inhibitor Subcommittee of the Association of Hemophilia Clinic Directors of Canada. Rituximab for congenital hemophiliacs with inhibitors: a Canadian experience. Haemophilia 2006;12(1):7-8.

\section{Collins 2009}

Collins PW, Mathias M, Hanley J, Keeling D, Keenan R, Laffan M, et al. Rituximab and immune tolerance in severe hemophilia A: a consecutive national cohort. Journal of Thrombosis and Haemostasis 2009;7(5):787-94.

\section{Cooper 2006}

Cooper N, Khair K, Mathias M, Leisner RI. Rituximab is effective and well tolerated in children with hemophilia and factor VIII inhibitors. Blood 2006;108:Abstract no: 1031.

\section{Coppola 2012}

Coppola A, Tagliaferri A, Di Capua M, Franchini M. Prophylaxis in children with hemophilia: evidence-based achievements, old and new challenges. Seminars in Thrombosis and Hemostasis 2012;38(1):79-94.

\section{DiMichele 2007}

DiMichele DM, Hoots WK, Pipe SW, Rivard GE, Santagostino E. International workshop on immune tolerance induction: consensus recommendations. Haemophilia 2007;13 Suppl 1:1-22.

\section{Egger 1997}

Egger M, Davey Smith G, Schneider M, Minder C. Bias in meta-analysis detected by a simple, graphical test. $B M J$ 1997;315(7109):629-34.

\section{FDA 2013}

Food, Drug Administration. Highlights of Prescribing Information (Rituxan). www.accessdata.fda.gov/ drugsatfda_docs/label/2013/103705s5409lbl.pdf (accessed 21 Augest 2013).

\section{Fox 2006}

Fox RA, Neufeld EJ, Bennett CM. Rituximab for adolescents with haemophilia and high titre inhibitors. Haemophilia 2006;12(3):218-22.

\section{Franchini 2008}

Franchini M, Mengoli C, Lippi G, Targher G, Montagnana M, Salvagno GL, et al. Immune tolerance with rituximab in congenital haemophilia with inhibitors: a systematic literature review based on individual patients analysis. Haemophilia 2008;14(5):903-12.

\section{Giulino 2007}

Giulino LB, Bussel JB, Neufeld EJ, Pediatric and Platelet Immunology Committees of the TMH Clinical Trial Network. Treatment with rituximab in benign and malignant hematologic disorders in children. Journal of Pediatrics 2007;150(4):338-44, 344. e1.

\section{Gouw 2007a}

Gouw SC, van der Bom JG, Marijke van den Berg H. Treatmentrelated risk factors of inhibitor development in previously untreated patients with hemophilia A: the CANAL cohort study. Blood 2007;109(11):4648-54.

\section{Gouw 2007b}

Gouw SC, van der Bom JG, Auerswald G, Ettinghausen CE, Tedgård $\mathrm{U}$, van den Berg HM. Recombinant versus plasmaderived factor VIII products and the development of inhibitors in previously untreated patients with severe hemophilia $A$ : the CANAL cohort study. Blood 2007;109(11):4693-7.

\section{Gouw 2013a}

Gouw SC, van den Berg HM, Fischer K, Auerswald G, Carcao M, Chalmers E, et al. Intensity of factor VIII treatment and inhibitor development in children with severe hemophilia A: the RODIN study. Blood 2013;121(20):4046-55.

\section{Gouw 2013b}

Gouw SC, van der Bom JG, Ljung R, Escuriola C, Cid AR, Claeyssens-Donadel S, et al. Factor VIII products and inhibitor development in severe hemophilia A. New England Journal of Medicine 2013;368(3):231-39.

\section{Grace 2012}

Grace RF, Bennett CM, Ritchey AK, Jeng M, Thornburg CD, Lambert MP, et al. Response to steroids predicts response to rituximab in pediatric chronic immune thrombocytopenia. Pediatric Blood \& Cancer 2012;58(2):221-5.

\section{Hay 2012}

Hay CR, DiMichele DM, on behalf of the International Immune Tolerance Study. The principal results of the International Immune Tolerance Study: a randomized dose comparison. Blood 2012;119(6):1335-44.

\section{Higgins 2011a}

Higgins JPT, Altman DG, Sterne JAC, editor(s). Chapter 8: Assessing risk of bias in included studies. In: Higgins JPT, Green S, editor(s). Cochrane Handbook for Systematic Reviews of Interventions Version 5.1.0 (updated March 2011). The Cochrane Collaboration, 2011. Available from www.cochranehandbook.org.

\section{Higgins 2011b}

Higgins JPT, Deeks JJ, Altman DG, editor(s). Chapter 16: Special topics in statistics. In: Higgins JPT, Green S, editor(s). Cochrane Handbook for Systematic Reviews of Interventions Version 5.1.0 (updated March 2011). The Cochrane Collaboration, 2011. Available from www.cochrane-handbook.org. 


\section{Iorio 2010a}

Iorio A, Halimeh S, Holzhauer S, Goldenberg N, Marchesini E, Marcucci M, et al. Rate of inhibitor development in previously untreated hemophilia A patients treated with plasma-derived or recombinant factor VIII concentrates: a systematic review. Journal of Thrombosis and Haemostasis 2010;8(6):1256-65.

\section{Iorio 2010b}

Iorio A, Matino D, D'Amico R, Makris M. Recombinant Factor VIla concentrate versus plasma derived concentrates for the treatment of acute bleeding episodes in people with haemophilia and inhibitors. Cochrane Database of Systematic Reviews 2010, Issue 8. [DOI: 10.1002/14651858.CD004449.pub3]

\section{Iorio 2011}

Iorio A, Marchesini E, Marcucci M, Stobart K, Chan AK. Clotting factor concentrates given to prevent bleeding and bleedingrelated complications in people with hemophilia A or B. Cochrane Database of Systematic Reviews 2011, Issue 9. [DOI: 10.1002/14651858.CD003429.pub4]

\section{Kavcic 2013}

Kavcic M, Fisher BT, Seif AE, Li Y, Huang YS, Walker D, et al. Leveraging administrative data to monitor rituximab use in 2875 patients at 42 freestanding children's hospitals across the United States. Journal of Pediatrics 2013;162(6):1252-8.

\section{Kobayashi 2015}

Kobayashi R, Sano H, Suzuki D, Kishimoto K, Yasuda K, et al. Successful treatment of immune tolerance induction with rituximab in a patient with severe hemophilia $B$ and inhibitor. Blood Coagulation and Fibrinolysis 2015;26(5):580-2.

\section{Kuzmanovic 2012}

Kuzmanovic M, Jurisic V. Rituximab for treatment of autoimmune hemolytic anemia. Indian Pediatrics 2012;49(8):672-4.

\section{Leissinger 2011}

Leissinger C, Gringeri A, Antmen B, Berntorp E, Biasoli C, Carpenter $\mathrm{S}$, et al. Anti-inhibitor coagulant complex prophylaxis in hemophilia with inhibitors. New England Journal of Medicine 2011;365(18):1684-92.

\section{Mateo 2006}

Mateo J, Badell I, Forner R, Borrell M, Tizzano E, Fontcuberta J. Successful suppression using Rituximab of a factor VIII inhibitor in a boy with severe congenital haemophilia: an example of a significant decrease of treatment costs. Thrombosis and Haemostasis 2006;95(2):386-7.

\section{Moschovi 2006}

Moschovi M, Aronis S, Trimis G, Platokouki H, Salavoura K, et al. Rituximab in the treatment of high responding inhibitors in severe haemophilia A. Haemophilia 2006;12(1):95-9.

\section{NCT01064284}

NCT01064284. Survey of inhibitors in plasma-product exposed toddlers (SIPPET). https://clinicaltrials.gov/ct2/show/ NCT01064284 (accessed 27 January 2015).

\section{NHLBI 2011}

U.S. National Heart Lung and Blood Institute. What is hemophilia?. http://www.nhlbi.nih.gov/health/health-topics/ topics/hemophilia/ (accessed 18 November 2012).

\section{Nwobi 2008}

Nwobi O, Abitbol CL, Chandar J, Seeherunvong W, Zilleruelo G. Rituximab therapy for juvenile-onset systemic lupus erythematosus. Pediatric Nephrology 2008;23(3):413-9.

\section{Pescovitz 2006}

Pescovitz MD. Rituximab, an anti-cd20 monoclonal antibody: history and mechanism of action. American Journal of Transplantation 2006;6(5 Pt 1):859-66.

\section{RevMan 2014 [Computer program]}

The Nordic Cochrane Centre, The Cochrane Collaboration. Review Manager (RevMan). Version 5.3. Copenhagen: The Nordic Cochrane Centre, The Cochrane Collaboration, 2014.

\section{Selewski 2010}

Selewski DT, Shah GV, Mody RJ, Rajdev PA, Mukherji SK. Rituximab (Rituxan). American Journal of Neuroradiology 2010;31(7):1178-80.

\section{Stedman 2011}

Stedman MR, Curtin F, Elbourne DR, Kesselheim AS, Brookhart MA. Meta-analyses involving cross-over trials: methodological issues. International Journal of Epidemiology 2011;40(6):1732-4

\section{Verbruggen 1995}

Verbruggen B, Novakova I, Wessels H, Boezeman J, van den Berg M, Mauser-Bunschoten E, et al. The Nijmegen modification of the Bethesda assay for factor VIII:C inhibitors: improved specificity and reliability. Thrombosis and Haemostasis 1995;73(2):247-51.

\section{WFH 2012a}

World Federation of Hemophilia. About bleeding disorders-How are inhibitors diagnosed?. www.wfh.org/en/page. aspx?pid=648 (accessed 18 November 2012).

\section{WFH 2012b}

World Federation of Hemophilia. About bleeding disorders-Who is at risk of developing inhibitors?. www.wfh.org/en/page.aspx? pid=653 (accessed in 19 Augest 2013).

\section{WFH 2013}

World Federation of Hemophilia. About bleeding disorders - What are inhibitors?. www.wfh.org/en/page.aspx?pid=651 (accessed 19 August 2013).

\section{Yadav 2012}

Yadav SP, Chinnabhandar C. Rituximab usage in children: a double edged sword. Indian Pediatrics 2012;49(4):335-6. 


\section{References to other published versions of this review}

\section{Liu 2013}

Liu Y, Zhang L, Santoro C, Song J, Rodriguez A, Wang L. Rituximab for treating inhibitors in children with hemophilia. Cochrane Database of Systematic Reviews 2013, Issue 10. [DOI: 10.1002/14651858.CD010810]

\section{A P P E N D I C E S}

\section{Appendix 1. Glossary of terms}

\begin{tabular}{ll}
\hline Term & Definition \\
\hline $\begin{array}{l}\text { Complement-dependent cyto- } \\
\text { toxicity (CDC) }\end{array}$ & $\begin{array}{l}\text { Binding of the antibody recruits complement proteins, which punch holes in the cell membrane, } \\
\text { flooding the cell and leading to cellysis. }\end{array}$ \\
\hline Apoptosis & Binding of the antibody signals the cell to self-destruct. \\
\hline $\begin{array}{l}\text { Antibody-dependent cell-me- } \\
\text { diated cytotoxicity (ADCC) }\end{array}$ & $\begin{array}{l}\text { Natural killer cells, T cells, and macrophages are involved in recognizing and killing antibody-la- } \\
\text { belled target cells, leading to cellysis. }\end{array}$ \\
\hline
\end{tabular}

\section{Liu 2015}

Liu Y, Zhang L, Santoro C, Song J, Rodriguez A, Wang L. Rituximab for treating inhibitors in people with inherited severe hemophilia. Cochrane Database of Systematic Reviews 2015, Issue 4. [DOI: 10.1002/14651858.CD010810.pub2]

\section{Appendix 2. Detailed search strategies}

\begin{tabular}{|c|c|c|c|}
\hline No. & PubMed & Embase & LILACS \\
\hline$\# 1$ & Hemophilia & Hemophilia & $\begin{array}{l}\text { Hemophil- } \\
\text { ia/Haemophilia }\end{array}$ \\
\hline \#2 & "Hemophilia A/drug therapy"[Mesh] & 'hemophilia'/exp & $\begin{array}{l}\text { Hemophil- } \\
\text { ia/Haemophilia }\end{array}$ \\
\hline \#3 & "Hemophilia B/drug therapy"[Mesh] & 'rituximab'/exp & Ritux\$ \\
\hline$\# 4$ & "rituximab" [Supplementary Concept] & Ritux $^{*}$ & rituximab \\
\hline \#5 & Ritux* & 'mabthera'/exp & \#1 OR \#2 \\
\hline \#6 & Mabthera & mabthera & \#3 OR \#4 \\
\hline$\# 7$ & $\begin{array}{l}\text { "Antibodies, Monoclonal, Murine-Derived/thera- } \\
\text { peutic use"[Mesh] }\end{array}$ & Antibodies & \#5 AND \#6 \\
\hline \#8 & \#1-\#3/OR & Monoclonal & \\
\hline \#9 & \#4-\#7/OR & Murine-Derived & \\
\hline$\# 10$ & \#8 AND \#9 & $\# 1$ OR \#2 & \\
\hline \#11 & & \#3-\#6/OR & \\
\hline$\# 12$ & & $\# 7-\# 9 / A N D$ & \\
\hline
\end{tabular}


(Continued)
$\# 13$
\#11 OR \#12

$\# 14$

\#10 AND \#13

\section{Appendix 3. Database weblink}

PubMed:www.ncbi.nlm.nih.gov/pubmed/

Embase:www.elsevier.com/online-tools/embase

LILACS:http://lilacs.bvsalud.org/en/

WHAT'S NEW

\begin{tabular}{lll}
\hline Date & Event & Description \\
\hline 6 July 2017 & New search has been performed & $\begin{array}{l}\text { A search of the Cochrane Cystic Fibrosis and Genetic Disorders } \\
\text { Coagulopathies Trials Register did not identify and potentially } \\
\text { eligible trials for inclusion in the update. Further searches did } \\
\text { not identify an trials eligible for inclusion in any section of the } \\
\text { review, other than a new case report that is referred to in the } \\
\text { 'Agreements and disagreements with other studies or reviews' } \\
\text { section. } \\
\end{array}$ \\
$\begin{array}{ll}\text { The author list has been updated. } \\
\text { Nuly } 2017\end{array}$ & $\begin{array}{l}\text { Minor changes to the text have been made throughout the re- } \\
\text { view. }\end{array}$ \\
\hline
\end{tabular}

CONTRIBUTIONS OF AUTHORS

\section{Roles and responsibilities}

\begin{tabular}{ll}
\hline Task & Who undertook the task? \\
\hline Protocol stage: draft the protocol & Yi Liu; Cristina Santoro; Armando Rodriguez \\
\hline Review stage: perform the searches & $\begin{array}{l}\text { Yi Liu; Cristina Santoro; Jie Song; Cochrane Cystic Fibrosis and Genetic Disorders } \\
\text { Group }\end{array}$ \\
\hline Review stage: perform the discussion & Yi Liu; Lingli Zhang; Cristina Santoro \\
\hline Review stage: perform the conclusion & Yi Liu; Lingli Zhang; Li Wang \\
\hline Review stage: draft the final review & Yi Liu; Lingli Zhang; Jie Song; Armando Rodriguez \\
\hline Update stage: update the review & Lucan Jiang; Yi Liu; Lingli Zhang; Cristina Santoro; Armando Rodriguez \\
\hline
\end{tabular}

\section{DECLARATIONS OF INTEREST}

All authors: none known. 


\section{SOURCES OF SUPPORT}

\section{Internal sources}

- Sichuan University, China.

Free Databases

- West China Second University Hospital,Sichuan University, China.

Free Database

\section{External sources}

- Natural Science Foundation of China: Evidence based establishment of evaluation index system for pediatric rational drug use in China (No. 81373381), China.

- National Institute for Health Research, UK.

This systematic review was supported by the National Institute for Health Research, via Cochrane Infrastructure funding to the Cochrane Cystic Fibrosis and Genetic Disorders Group.

\section{DIFFERENCES BETWEEN PROTOCOLANDREVIEW}

- The authors and editorial team agreed to expand the review from including children only, to include people of all ages.

- The third authors' detail has been changed from "West China Second University Hospital, Sichuan University" to "West China College of Pharmacy, Sichuan University".

- Because of this empty review, the contributions of authors have changed.

\section{N DEX TERMS}

\section{Medical Subject Headings (MeSH)}

*Antibodies; Factor IX [antagonists \& inhibitors] [*immunology]; Factor VIII [antagonists \& inhibitors] [“immunology]; Hemophilia A [blood] [ ${ }^{\star}$ drug therapy]; Hemophilia B [blood] [*drug therapy]; Immunologic Factors [*therapeutic use]; Rituximab [ ${ }^{\star}$ therapeutic use]

\section{MeSH check words}

Humans 